\title{
Current Sensorless MPPT Control Method for Dual-Mode PV Module-Type Interleaved Flyback Inverters
}

\author{
June-Hee Lee*, June-Seok Lee ${ }^{*}$, and Kyo-Beum Lee ${ }^{\dagger}$ \\ ${ }^{* \dagger}$ Department of Electrical and Computer Engineering, Ajou University, Suwon, Korea
}

\begin{abstract}
This paper presents a current sensorless maximum power point tracking (MPPT) control method for dual-mode photovoltaic (PV) module-type interleaved flyback inverters (ILFIs). This system, called the MIC (Module Integrated Converter), has been recently studied in small PV power generation systems. Because the MIC is an inverter connected to one or two PV arrays, the power system is not affected by problems with other inverters. However, since the each PV array requires an inverter, there is a disadvantage that the initial installation cost is increased. To overcome this disadvantage, this paper uses a flyback inverter topology. A flyback inverter topology has an advantage in terms of cost because it uses fewer parts than the other transformer inverter topologies. The MPPT control method is essential in PV power generation systems. For the MPPT control method, expensive dc voltage and current sensors are used in the MIC system. In this paper, a MPPT control method without current sensor where the input current is calculated by a simple equation is proposed. This paper also deals with dual-mode control. Simulations and experiments are carried out to verify the performance and effectiveness of the proposed current sensorless MPPT control method on a $110[\mathrm{~W}]$ prototype.
\end{abstract}

Key words: Boundary conduction mode (BCM), Current sensorless MPPT, Discontinuous conduction mode (DCM), Dual-mode, Interleaved flyback inverter (ILFI), Photovoltaic (PV)

\section{INTRODUCTION}

Recently, alternative and renewable energy has been rapidly growing due to the depletion of fossil fuels and increasing environmental pollution. Sunlight is clean and unlimited. Photovoltaic (PV) technology generates electricity by using sunlight. It is easy to maintain, can be automated, and has a long life cycle (over 20 years). Therefore, many techniques have been researched in the area of PV power generation [1]-[4].

A PV power converter system (PV-PCS) uses a variety of methods to connect PV array modules and the PCS: central inverters, multi-string inverters, string inverters, and module integrated converters (MICs). A central inverter is connected to many PV modules in series and parallel. Although the

Manuscript received May 31, 2014; accepted Aug. 21, 2014

Recommended for publication by Associate Editor Liqiang Yuan.

${ }^{\dagger}$ Corresponding Author: kyl@ajou.ac.kr

Tel: +82-31-219-2376, Fax: +81-31-212-9531, Ajou University

*Dept. of Electrical and Computer Eng., Ajou University, Korea large central inverter method offers more economic advantages with increasing size, this approach offers poor energy harvesting because there is one centralized maximum power point tracking (MPPT) for the whole system. Moreover, partial shading and any mismatch between the PV modules can reduce efficiency [5]. A string inverter is another configuration for PV systems where a string of PV modules are connected to a single inverter integrated with MPPT. Therefore, the string inverter can avoid most of the weaknesses of the central inverter [6]. A multistring inverter consists of parallel connected DC/DC converters and a single $\mathrm{DC} / \mathrm{AC}$ inverter. The multistring inverter, which can control each PV module independently, combines the advantages of string and central inverters [7].

The MIC has several advantages over conventional central inverters. First, small amounts of shading, debris or snow on any one solar panel cannot reduce the output of the entire array. Second, the MIC is easy to install because a dc line is not required. Third, it provides maximum efficiency at the 


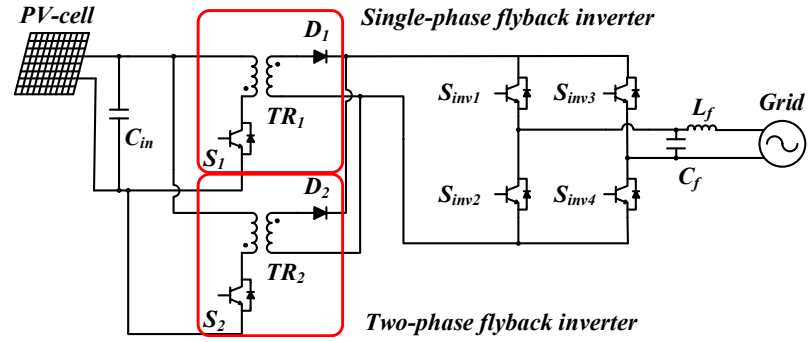

Fig. 1. Grid-connected ILFI.

maximum power point (MPP) and can reduce the price of the inverters because they can be produced on a large scale. Therefore, many studies on the MIC have been reported recently [8], [9].

A MIC is a type of controller where one or two PV arrays connect to inverters. Currently, many studies on MIC control methods represent two reference methods: the discontinuous conduction mode (DCM) and the boundary conduction mode (BCM). The dominant losses of MICs under light loads include the switch turn-off losses of the switch and the transformer core loss. Meanwhile, the dominant losses of MICs under heavy loads include the conduction losses of the switch and diode, and the core and copper losses of the transformer. Therefore, the system losses can be considerably reduced if the system operates in the DCM under light loads and in the BCM under heavy loads. The method used in this paper is a dual-mode control method [10]-[12].

A PV-PCS is affected by temperature and solar radiation as well as its available time is limited. Moreover, PV arrays have nonlinear power versus voltage characteristics. Therefore, the MPPT control method of a PV array is an essential part of a PV system. There are numerous studies on different types of MPPT control methods such as perturbation and observation $(\mathrm{P} \& \mathrm{O})$ [13], [14], incremental conductance (INC) [15], incremental resistance (INR) [16], open-circuit voltage [17], short-circuit current [18], hill climbing [19], neural network [20], fuzzy logic control [21] and $\beta$ method [22].

The conventional MPPT control method for the MIC requires input or output voltage and current. After obtaining data from the sensors, the system is controlled using the $\mathrm{P} \& \mathrm{O}$ MPPT control method. In this case, expensive dc voltage and current sensor are used [23], [24]. In a small PV power generation system with the MIC, the cost and size are important factors of the system. By reducing the number of parts, for example the input current sensor, the system advantage is a smaller size and a lower cost. Therefore, a current sensorless MPPT control method for the interleaved flyback inverter (ILFI) with dual-mode control is proposed in this paper.

\section{DUAL-MODE CONTROL FOR THE ILFI}

Fig. 1 shows a PV ILFI with a grid-connection. A current

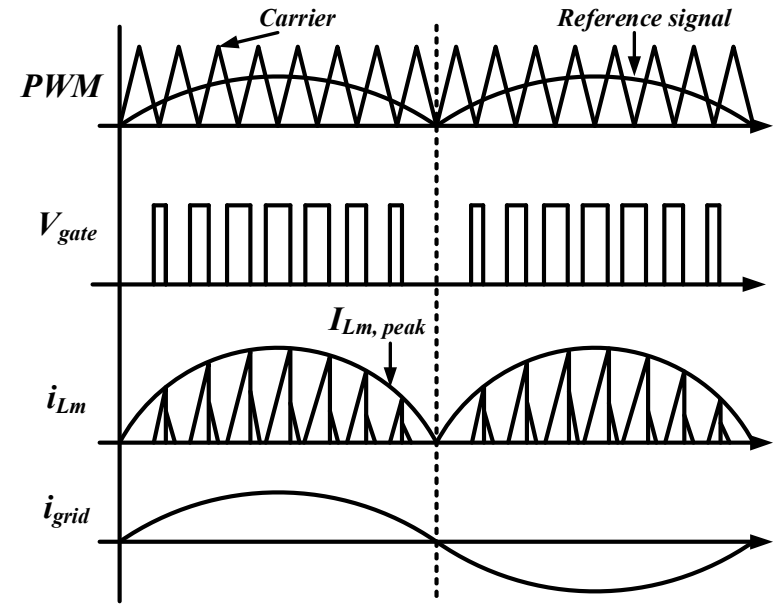

Fig. 2. DCM operation.

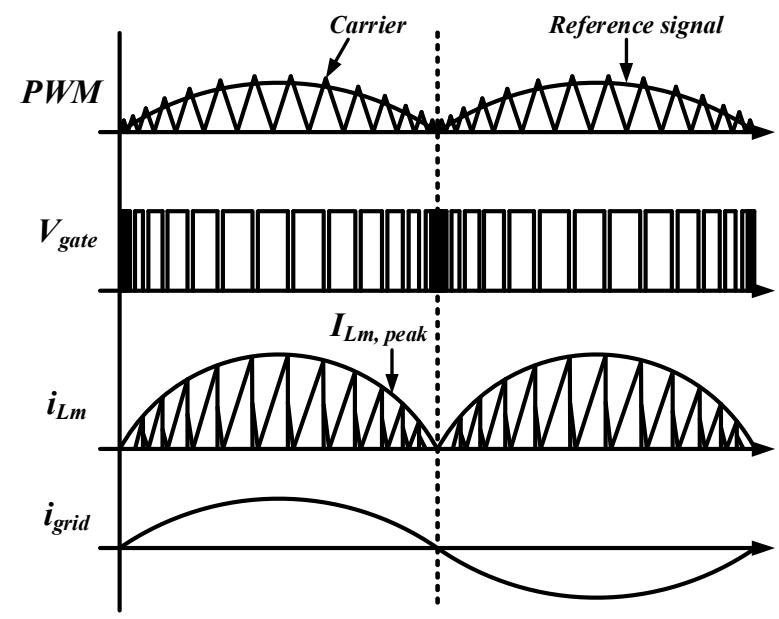

Fig. 3. BCM operation.

source inverter (CSI) flyback topology is used in this paper. The system consists of interleaved flyback inverters (with primary-side switches $S_{l}$ and $S_{2}$, transformers $T R_{l}$ and $T R_{2}$, and secondary-side diodes $D_{1}$ and $D_{2}$ ), an H-bridge inverter, and an output C-L filter. For reducing current ripple, interleaved control is used in this system. The interleaved control is a method where the current is divided into the single-phase and two-phase flyback inverters, which are shifted by $180^{\circ}$. Furthermore, by using the interleaved operation, the losses of each switch can be reduced [25]. The H-bridge inverter is built with four switches $\left(S_{i n v I}-S_{i n v 4}\right)$. When switches $S_{i n v 1}$ and $S_{i n v 4}$ are on ( $S_{i n v 2}$ and $S_{i n v 3}$ are off), a positive voltage will be applied across the grid. When switches $S_{i n v 1}$ and $S_{i n v 4}$ are off $\left(S_{i n v 2}\right.$ and $S_{i n v 3}$ are on), the voltage is reversed.

Fig. 2 shows the DCM operation. If the secondary current is allowed to discharge completely to zero, the system works in the DCM operation. Generally, the DCM operation is used to control ILFIs because it is very simple. Furthermore, this mode can reduce the frequency-dependent, turn-off, and transformer core losses at light loads [8].

Fig. 3 shows the BCM operation. If the secondary current 


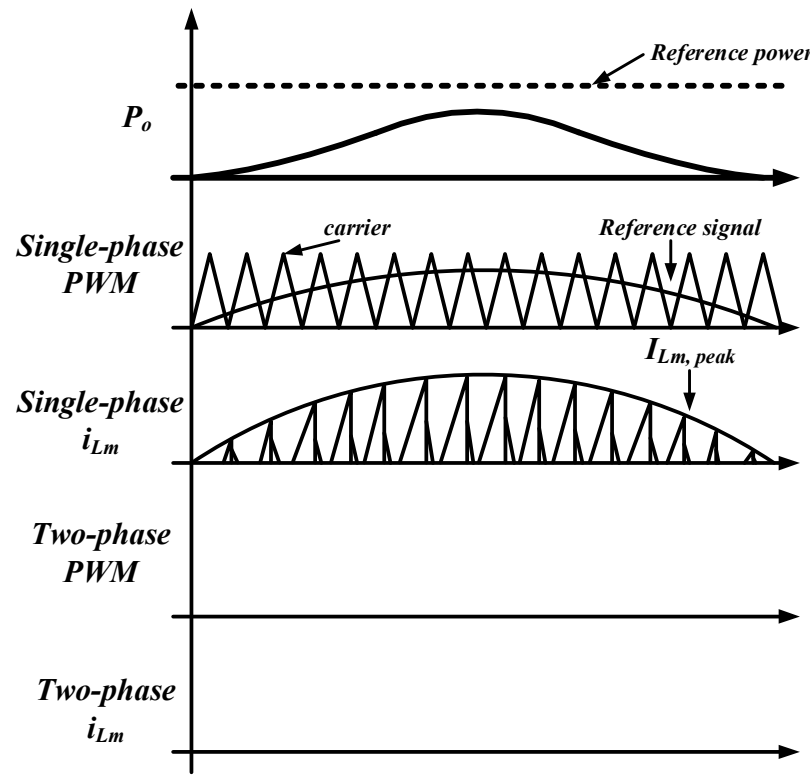

(a)

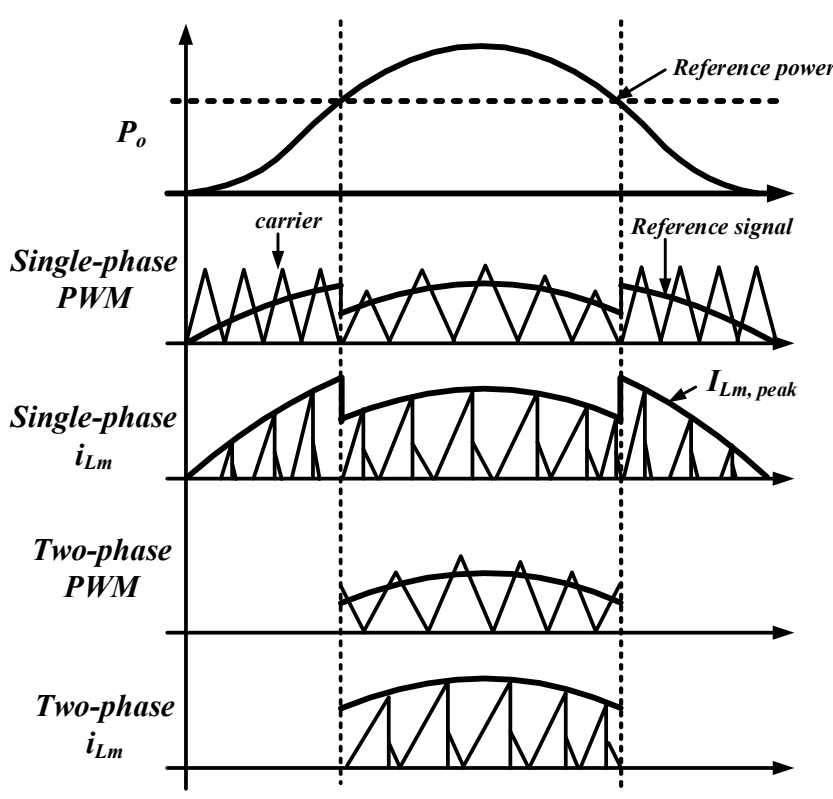

(b)

Fig. 4. Operations waveform of the ILFI (a) Single-phase DCM operation, (b) Dual-mode operation.

is allowed to discharge completely to zero, the primary current increases immediately. As a result, the switching frequency is always changed. Therefore, the BCM operation is more complicated than the DCM operation. However, when the load is heavy, the BCM operation is more suitable than the DCM operation because the transformer loss and size can both be reduced [8]. The system used in this paper operates in the dual mode by taking advantage of both modes. The dual mode indicates that the single-phase DCM operation is applied at a flyback inverter during the light load interval, and the interleaved BCM operation is applied at two flyback inverters during the heavy load interval.

Fig. 4 shows the dual-mode operation. The boundary condition of the dual-mode control is important for the design of the system. However, the optimal reference power between the BCM and DCM operations is not clarified in terms of the ILFI [26]. Therefore, in this paper, the boundary point design refers to [9]. As a result, the reference power is selected at $50 \%$ of the output power.

\section{A. Modeling of the Single-phase DCM Operation}

If the output power is lower than the reference power, the single-phase DCM operation is applied. Therefore, the duty ratio is a variable value, but the switching frequency is fixed. To calculate the duty ratio, the output voltage, which is the grid voltage $\left(V_{o}\right)$, of the flyback inverter is determined as:

$$
V_{o}=n \cdot \frac{D}{1-D} \cdot V_{p v}
$$

where $n$ is the turn ratio of the transformer. Here, $V_{p v}$ is the input voltage, and $D$ is the duty ratio.

The maximum duty ratio for the DCM operation is given by:

$$
D_{\max }=\frac{V_{o, p e a k}}{n V_{p v}+V_{o, p e a k}} .
$$

$V_{o, p e a k}$ is the peak value of the output voltage. The duty ratio for the DCM operation is always less than $D_{\max }$ and it can be given by:

$$
D<\frac{V_{o, p e a k}}{n V_{p v}+V_{o, p e a k}} .
$$

In the DCM operation, the duty ratio is varied while the switching frequency is constant.

\section{B. Modeling of the Interleaved BCM Operation}

The BCM operation has some advantages in terms of a higher power transfer and a smaller THD than the DCM operation because the BCM operation uses a maximum duty ratio. Therefore, the $\mathrm{BCM}$ operation takes a higher modulation than the DCM operation.

If the output power is greater than the reference power, the interleaved BCM operation is applied at the ILFI. The BCM operation must change the duty ratio and the switching frequency when the secondary current drops to zero.

First, the peak value of the primary current $\left(I_{L m, \text { peak }}\right)$ of the flyback inverter is given as:

$$
I_{L m, \text { peak }}=\frac{V_{i}}{L_{m}} t_{o n}=\frac{V_{i}}{L_{m}} D T
$$

where $t_{o n}$ is the switch-on time, and $T$ is the switching period. The primary current $\left(i_{L m}\right)$ has a sinusoidal waveform and is expressed as:

$$
i_{L m}(t)=I_{L m, p e a k} \sin \omega t, 0 \leq \omega t \leq 2 \pi .
$$

The duty cycle has to be modified and can be given as:

$$
d(t)=D_{\max } \sin \omega t, 0 \leq \omega t \leq 2 \pi
$$

where $D_{\max }$ is the duty cycle value of the switching cycle at 


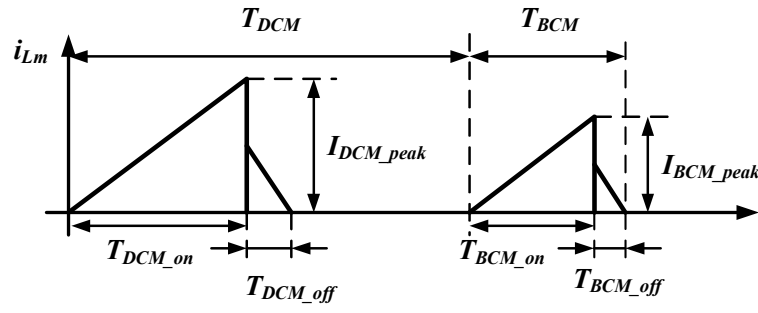

Fig. 5. Operation principle of the DCM and BCM operations.

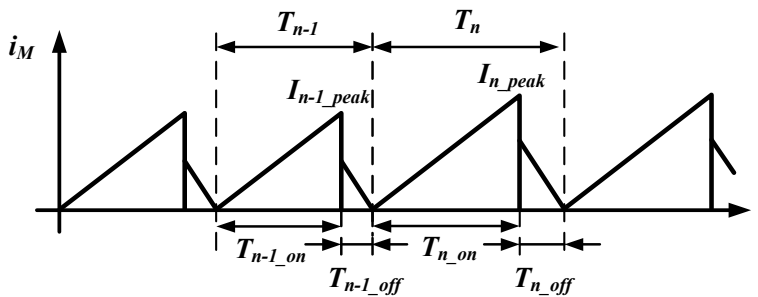

Fig. 6. Operation principle of the $\mathrm{BCM}$ operation.

$\omega t=\pi / 2$.

By combining (1), (4), and (6), the switching period for the $\mathrm{BCM}$ operation is calculated as:

$$
T=\frac{L_{m}}{V_{i} \cdot d(t)} I_{L m, \text { peak }} .
$$

From (7), the variable switching time for the BCM operation can be calculated. In the BCM operation, the square root of $I_{\text {Lm,peak }}$ is taken because the interleaved BCM operation is applied.

Fig. 5 shows the transformer current during one switching cycle in the DCM and BCM operations. $I_{D C M \text {,peak }}$ shows the primary peak current of the transformer in the DCM operation. $T_{D C M}$ shows the switching period in the DCM operation. $T_{D C M_{-} \text {on(off) }}$ shows the switch-on(off) time in the DCM operation. $I_{B C M \text {,peak }}$ shows the primary peak current of the transformer in the $\mathrm{BCM}$ operation. $T_{B C M}$ shows the switching period in the BCM operation. $T_{B C M_{-} \text {on(off) }}$ shows the switch-on(off) time in the BCM operation. Equations (8) and (9) represent average primary current during the DCM and $\mathrm{BCM}$ operations, respectively, for one switching cycle.

$$
\begin{gathered}
I_{D C M, \text { avg }}=\frac{I_{L m, D C M, \text { peak }} \cdot T_{D C M, \text { on }}}{2 T_{D C M}}=\frac{I_{L m, D C M, \text { peak }} \cdot D_{D C M}}{2} \\
I_{B C M, \text { avg }}=\frac{I_{L m, B C M, \text { peak }} \cdot T_{B C M, \text { on }}}{2 T_{B C M}}=\frac{I_{L m, B C M, \text { peak }} \cdot D_{B C M}}{2} .
\end{gathered}
$$

For the same output power between the DCM and BCM operations, the primary average currents during one switching cycle of each mode are the same. Hence, by combining (4), (8), and (9), the BCM operation duty ratio $\left(D_{B C M}\right)$ is expressed as:

$$
D_{B C M}=D_{D C M} \cdot \sqrt{\frac{T_{D C M}}{T_{B C M}}} .
$$

As shown in Fig. 6, in the BCM operation, the new duty ratio is used by (8)-(10). Therefore, the system can operate in dual modes by using (1), (7), and (10).

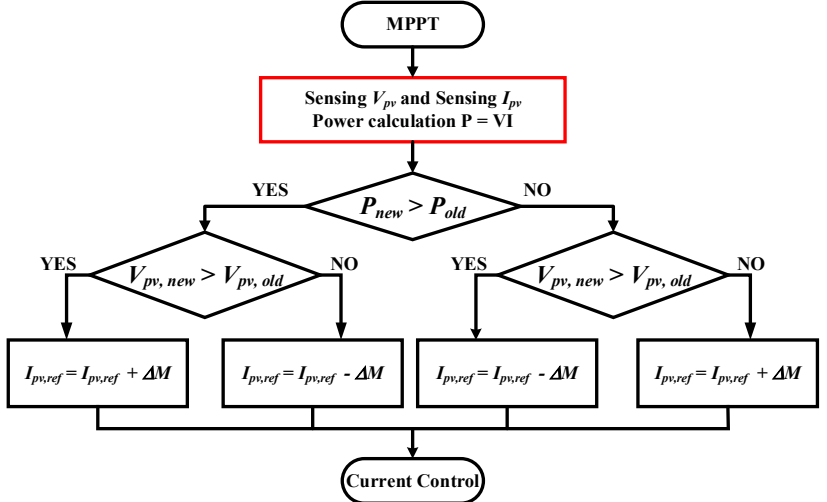

Fig. 7. Flowchart of the conventional MPPT control method.

To use the dual mode, the power $\left(P_{\text {out }}\right)$ is calculated instantaneously, and the reference power $\left(P_{r e f}\right)$ decides the operation mode. From $V_{p v}$ and the primary average current $\left(I_{\text {avg }}\right)$ of (8) and (9), $P_{\text {out }}$ is given as:

$$
P_{\text {out }}=V_{p v} \cdot I_{\text {avg }} \text {. }
$$

If $P_{\text {out }}$ is less than $P_{\text {ref }}$ (a light load), the single-phase DCM operation is applied at one flyback inverter. On the other hand, if $P_{\text {out }}$ is greater than $P_{\text {ref }}$ (a heavy load), the interleaved $\mathrm{BCM}$ operation is applied at two flyback inverters.

\section{CURRENT SENSORLESS MPPT CONTROL METHOD FOR THE PV MODULE-TYPE DUAL-MODE ILFI}

The P\&O MPPT control method is generally used in maximum power transfer systems because of its simple feedback structure and ease of control.

The input current, which used in the conventional sensorless control, is calculated by the electric charge [23]. In this case, the equation for the input current is more complicated. However, in this paper, the input current is calculated more simply by using the average current in the DCM operation by (8) and in the BCM operation by (9). The MPPT control method uses the calculated average current which is divided by a half-grid period. Therefore, the proposed method is more simplified than the conventional sensorless control.

Fig. 7 shows a flowchart of the P\&O MPPT control method and Fig. 8 shows the P-V-I (power, voltage, current) curve of the P\&O MPPT control method. By using the PV voltage and PV current through the voltage and current sensors, $P_{\text {out }}$ can be expressed as (11). After calculating the PV power variation and PV voltage variation from (11) and the PV voltage, the output power can reach the MPP by varying the perturbation $(\Delta M)$. For example, in Fig. 8, the new state is point $B$ and the previous state is point $A$. Then the PV power variation will be a positive state and the PV voltage variation will be a negative state. In this case, the PV current must be increased up to the MPP. Therefore, it is 


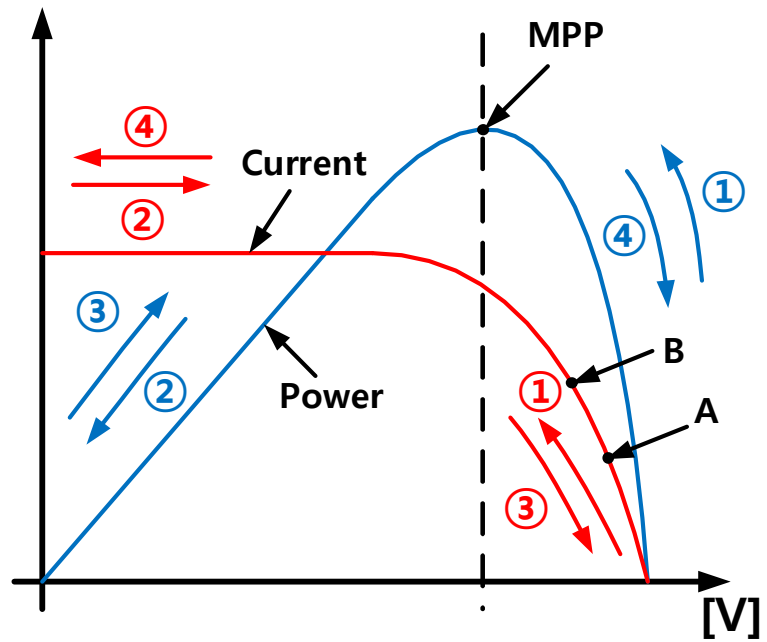

Fig. 8. P-V-I (power, voltage, current) curve of the P\&O MPPT control method.

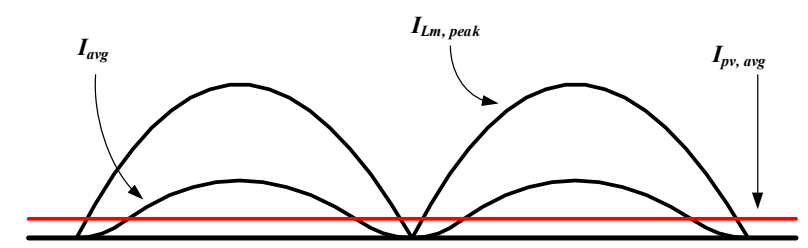

Fig. 9. Average current per half-grid frequency for MPPT control method.

necessary to increase the reference current.

In the conventional P\&O MPPT control method, the PV output power, which is given by the product of the PV voltage and PV current, must be calculated. Usually, current sensors are expensive and bulky. As a result, they have an effect on the cost of the whole system. Therefore, an alternative method is required to reduce both the cost and system size. In this paper, the proposed method calculates the PV current from the average value of the current. Therefore, the maximum power is calculated with the PV voltage and calculated current.

For the MPPT control method, initially, the PV output current is calculated using the switching frequency and duty cycle, as given in (8) and (9). The average value of the primary current $\left(I_{p v, a v g}\right)$ for half of a grid period is calculated as:

$$
I_{p v, a v g}=\frac{\int_{0}^{T_{\text {half of grid }}} I_{a v g} d t}{T_{\text {half of grid }}}
$$

where $T_{\text {half of grid }}$ denotes half a period of the grid and $I_{p v, \text { avg }}$ is the dc value in (12), as shown in Fig. 9.

Fig. 10 shows the operation of the current sensorless MPPT control method. First, the PV output power $\left(P_{p v}\right)$, given by (13), is calculated from the product of the measured PV voltage and the calculated PV current as:

$$
P_{p v}=V_{p v} \cdot I_{p v, a v g} .
$$

After the microcontroller unit (MCU) has memorized the

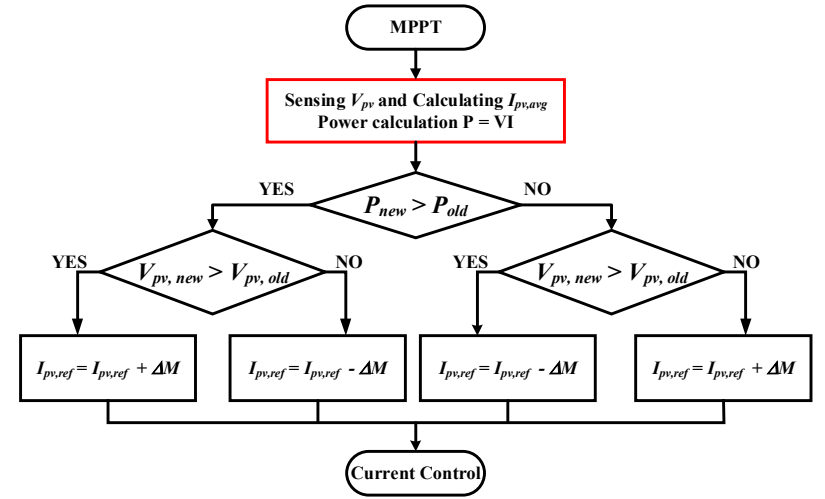

Fig. 10. Flowchart of the current sensorless MPPT control method.

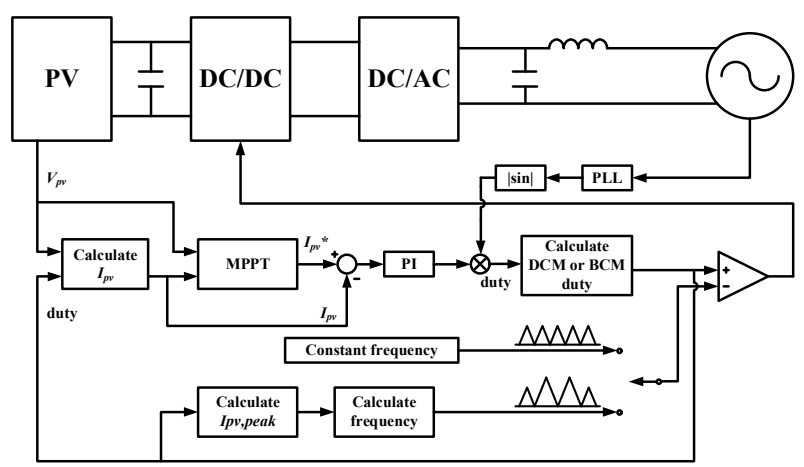

Fig. 11. Block diagram of the proposed method.

previous PV output power $\left(P_{\text {old }}\right)$ and PV voltage $\left(V_{p v, o l d}\right)$, the reference current $\left(I_{p v, r e f}\right)$ is calculated by comparing them with the present PV output power $\left(P_{\text {new }}\right)$ and PV voltage $\left(V_{p v, \text { new }}\right)$ for the MPPT control method.

Fig. 11 shows a block diagram of the proposed dual-mode current sensorless MPPT control method for the ILFI. By using the measured PV voltage and the calculated PV current, the duty ratio of each mode is obtained by $I_{p v, r e f}$ through the PI current controller. Finally, by using the duty ratio of each mode and the constant or calculated frequency, the system operates in the proposed algorithm.

\section{SiMULATION}

Simulations are performed using PSIM tool in this paper. The PV module-type ILFI with a dual mode topology, shown in Fig. 1, is used in the simulation. The simulation parameters are listed in Table I. $C_{i n}$ shows the input capacitor, $C_{f}$ shows the capacitor of the CL filter, $L_{f}$ shows the inductor of the CL filter. $L_{m}$ and $L_{l k}$ are the transformer parameters, $L_{m}$ is the magnetic inductance, and $L_{l k}$ is the leakage inductance.

Fig. 12 shows the operation of the ILFI with dual mode control. $V_{\text {grid }}$ and $I_{\text {grid }}$ are the grid voltage and grid current, respectively. $I_{p, s l}$ is the primary current of the single-phase transformer, and $I_{s, s 1}$ is its secondary current. $I_{p, s 2}$ and $I_{s, s 2}$ are the primary current and secondary current of the two-phase 

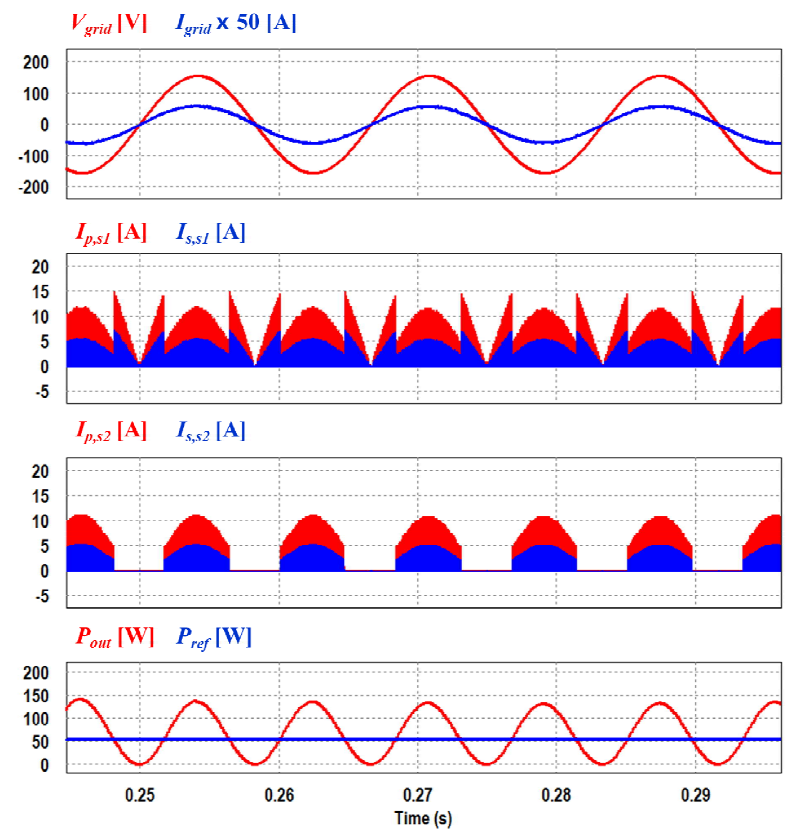

Fig. 12. Waveforms of the dual-mode ILFI.

TABLE I

PARAMETERS FOR THE SIMULATIONS AND EXPERIMENT

\begin{tabular}{c|c||c|c}
\hline $\boldsymbol{V}_{\text {grid }}$ & $\begin{array}{c}110 \mathrm{~V}_{\mathrm{ac}} \\
(60 \mathrm{~Hz})\end{array}$ & $\boldsymbol{P}_{\boldsymbol{o}}$ & $110 \mathrm{~W}$ \\
\hline $\boldsymbol{V}_{\boldsymbol{p v}(\boldsymbol{d c})}$ & $20 \sim 33 \mathrm{~V}_{\mathrm{dc}}$ & $\begin{array}{c}\text { Transformer } \\
\text { turn ratio }\end{array}$ & $1: 2$ \\
\hline $\boldsymbol{C}_{\boldsymbol{i n}}$ & $10.1 \mathrm{mF}$ & $\boldsymbol{L}_{\boldsymbol{m}}$ & $13.99 \mu \mathrm{H}$ \\
\hline $\boldsymbol{C}_{\boldsymbol{f}}$ & $0.22 \mu \mathrm{F}$ & $\boldsymbol{L}_{\boldsymbol{l k}}$ & $0.01 \mu \mathrm{H}$ \\
\hline $\boldsymbol{L}_{\boldsymbol{f}}$ & $1 \mathrm{mH}$ & $\boldsymbol{f}_{\boldsymbol{D C M}}$ & $50 \mathrm{kHz}$ \\
\hline
\end{tabular}

transformer, respectively. $P_{\text {out }}$ is the output power calculated from (11), and $P_{r e f}$ is the boundary value to separate the operation modes. In this paper, $P_{\text {ref }}$ is set to 55 [W]. Therefore, the single-phase DCM operation is applied below $P_{\text {ref }}$ whereas the two-phase interleaved BCM operation is applied above $P_{\text {ref }}$, as shown in Fig. 12. Once the system enters the two-phase interleaved BCM operation, the frequency and duty ratio are changed by (7) and (10). Using (7), the maximum frequency, $f_{\max }$, is about $200[\mathrm{kHz}]$ and the minimum frequency, $f_{\min }$, is about $120[\mathrm{kHz}]$.

Fig. 13 shows closed waveforms of the ILFI with dual mode control when the mode is changed. $V_{\text {gate,s } 1}$ and $V_{\text {gate, } s 2}$ are the switching signals for $S_{1}$ and $S_{2}$, respectively. Fig. 13(a) shows that the operation mode is changed from the single-phase DCM operation to the interleaved BCM operation. If the mode enters the interleaved BCM operation, $I_{\text {Lm,peak }}$ and the frequency for the BCM operation are calculated. Consequently, a new gate signal is sent to the switches. On the other hand, as shown in Fig. 13(b), when the mode changes from the interleaved BCM operation to the single-phase DCM operation, the two-phase flyback inverter switch, $S_{2}$, turns off.

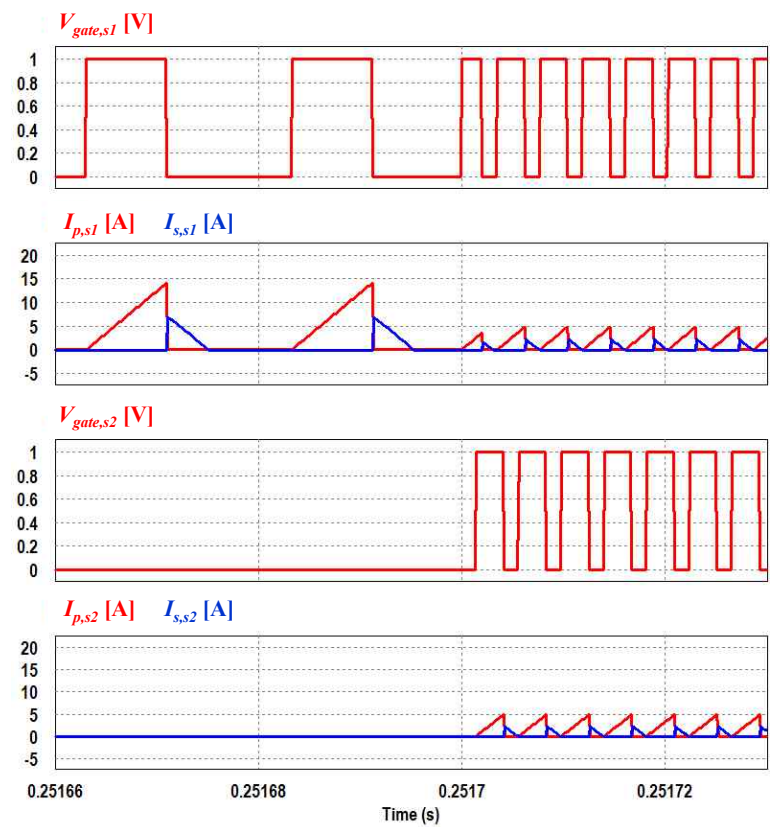

(a)
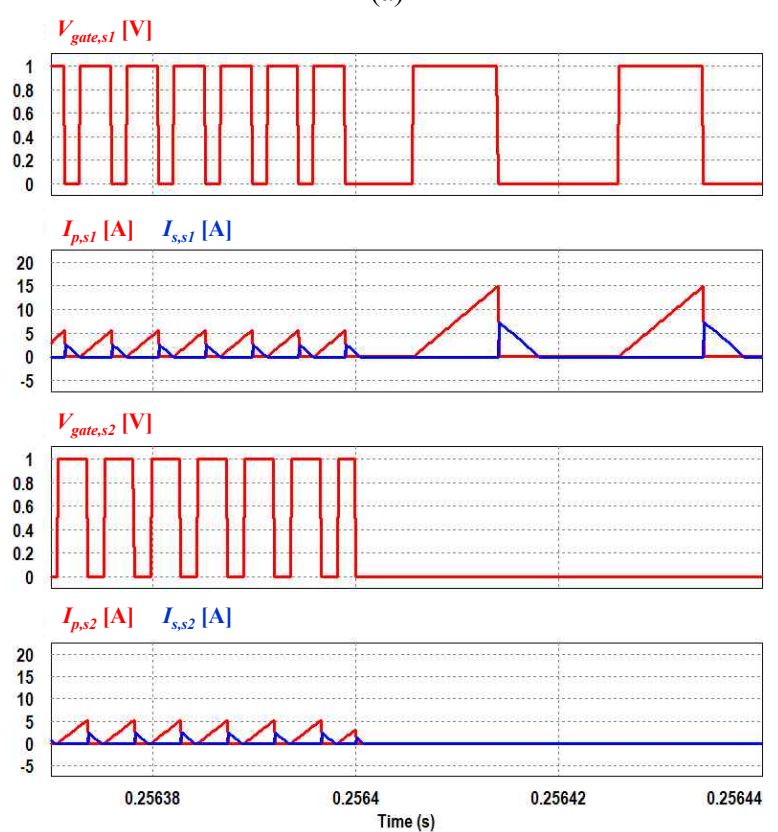

(b)

Fig. 13. Closed waveforms of the dual-mode ILFI. (a) Change from single-phase DCM to interleaved BCM. (b) Change from interleaved BCM to single-phase DCM.

Fig. 14 shows the key waveform of the system operation. $I_{\text {Lm,peak }}$ is the calculated value from (4). Using this value, $I_{p v, a v g}$ is calculated by (12). Further, $I_{p v, a v g}$ is the dc value that is applied to the current sensorless MPPT control method.

Fig. 15 shows the performance of a MATLAB PV module simulation. In this simulation, the MPP voltage is 25 [V], and the MPP current is 4.503 [A]. Fig. 16 shows the proposed MPPT control method. The duty ratio is calculated with $I_{r e f}$, which is generated by the MPPT, and $I_{p v, a v g}$ from (12). As shown in Fig. 16, it is confirmed that $I_{p v, a v g}$ follows $I_{r e f}$. It can 


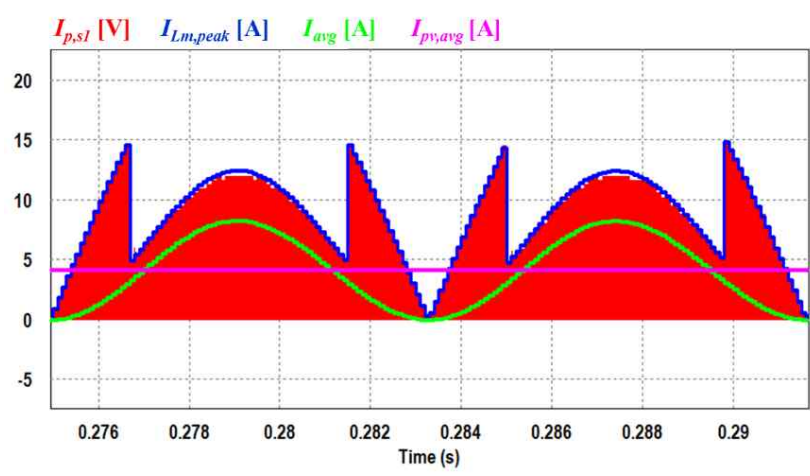

Fig. 14. Key waveform of the dual-mode ILFI.

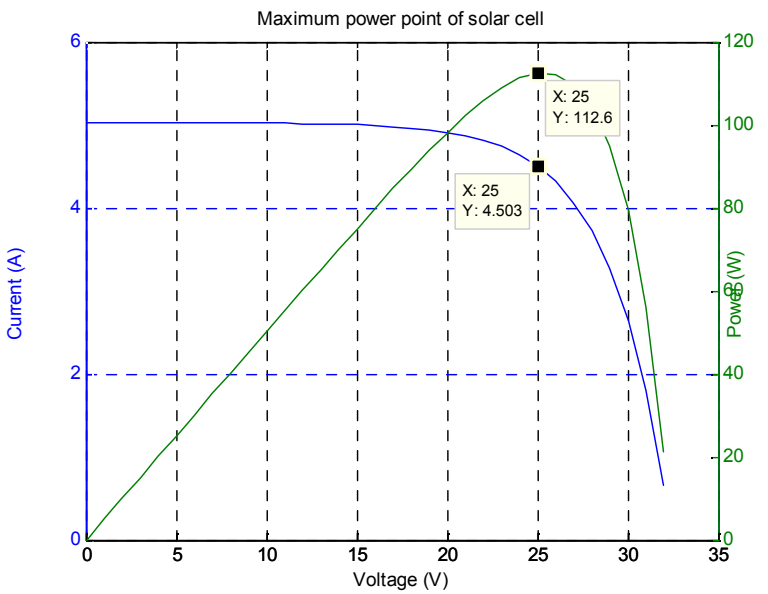

Fig. 15. MATLAB PV module simulation results of the proposed MPPT control method.
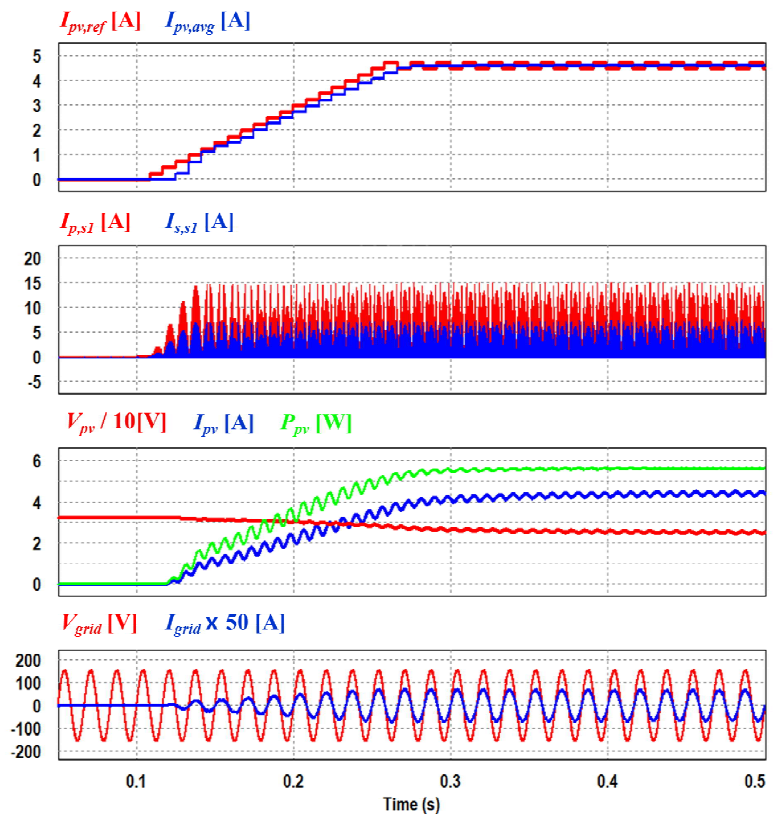

Fig. 16. Waveform of the proposed current sensorless MPPT control method in the dual-mode ILFI.

also be seen that $I_{\text {grid }}$ increases when the system power increases. Moreover, the phase of the grid voltage is the same as that of the grid current.

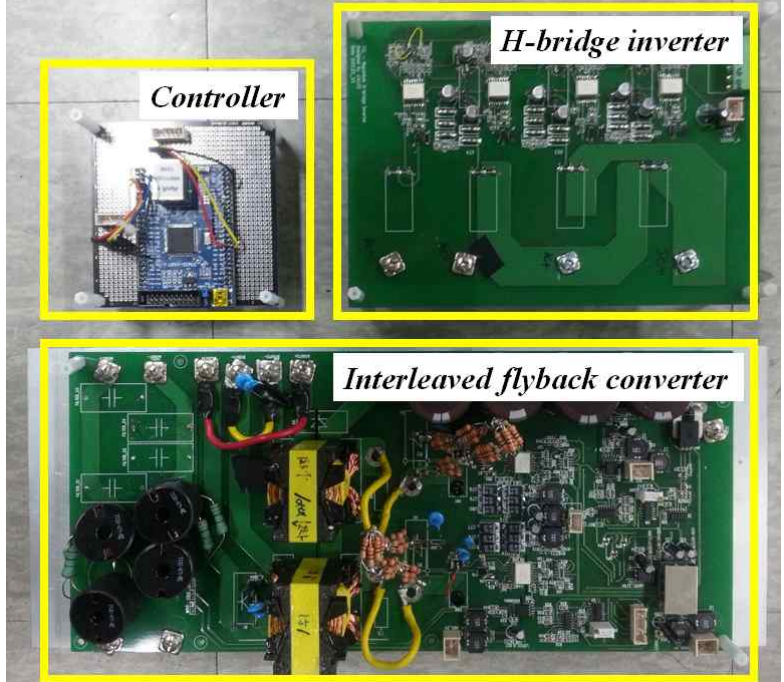

Fig. 17. Experimental equipment.

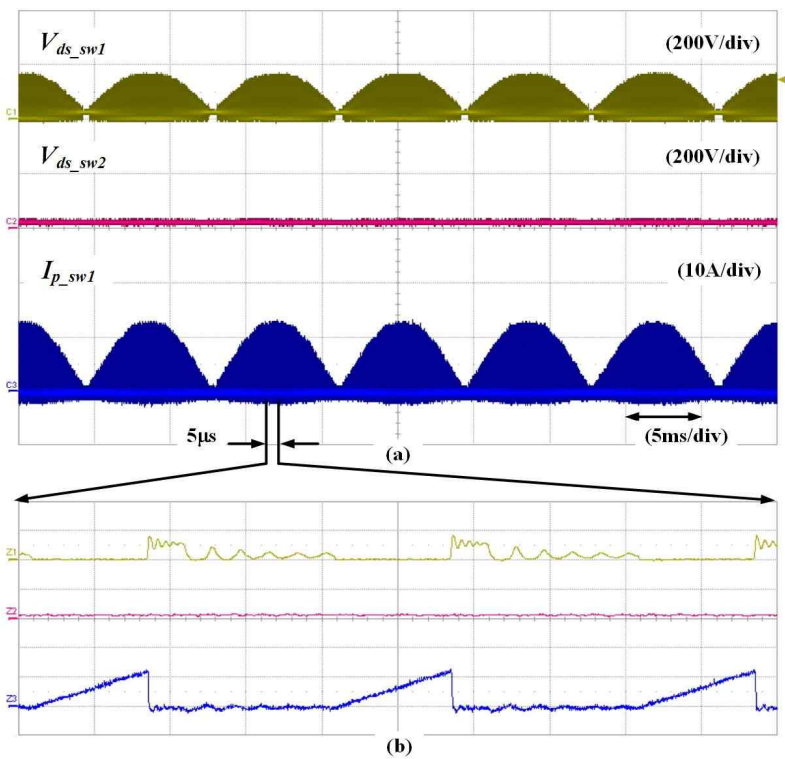

Fig. 18. Experimental waveforms of the single-phase DCM operation. (a) Whole operation waveform. (b) Closed waveform.

\section{EXPERIMENTAL RESULTS}

Experiments are performed to verify the proposed current sensorless MPPT control scheme. Fig. 17 shows the experimental system configuration. The experimental system consists of an interleaved flyback converter board, an H-bridge inverter board, and a controller module. An ARM cortex-M4 STM32F407VGT from ST Microelectronics is used as the controller module. The parameters for the experimental setup are the same as those used in the simulations. Usually, the power capacity of the MIC, which is connected to one or two PV arrays, is decided according to the PV output power capacity. Therefore, in this paper, the experiment is verified under the $110[\mathrm{~W}]$ of the prototype.

Fig. 18(a) shows the experimental whole waveforms of the ILFI with dual mode in the DCM operation, and Fig. 18(b) 


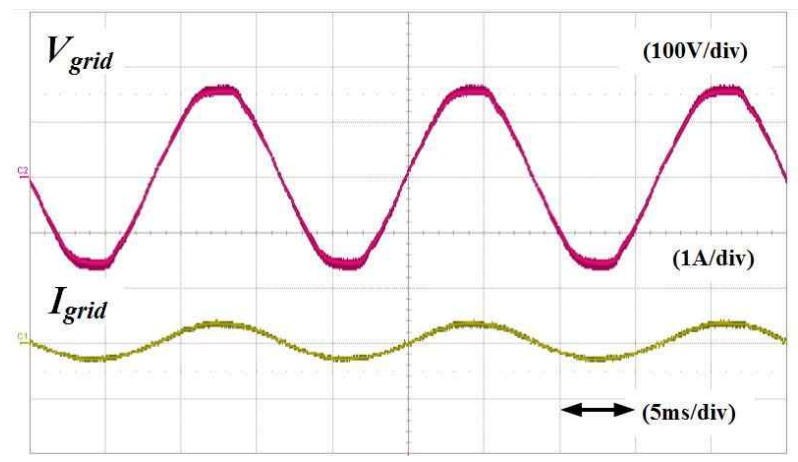

Fig. 19. Grid voltage and grid current waveforms of the single-phase DCM operation.

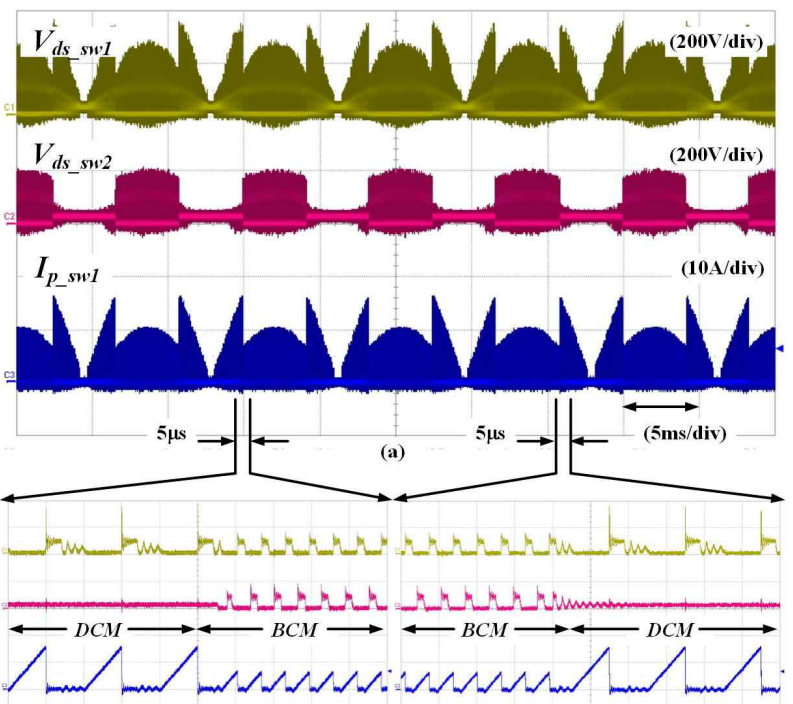

(b)

Fig. 20. Experimental waveforms of the dual-mode ILFI. (a) Whole operation waveform. (b) Change from single-phase DCM to interleaved BCM. (c) Change from interleaved $\mathrm{BCM}$ to single-phase BCM.

shows experimental closed waveforms of the same operation. Fig. 19 shows the experimental grid voltage and grid current waveforms in the DCM operation. As can be seen, $P_{\text {out }}$, which is the product of the grid voltage and the grid current, does not exceed $P_{\text {ref. }}$. Therefore, the system operates in the DCM operation. When the system operates in the DCM operation, it is operated as a single-phase flyback inverter.

Fig. 20(a) shows experimental waveforms of the ILFI with dual mode. In this figure, the drain-source voltages of the main switches $\left(V_{S 1, d s}\right.$ and $\left.V_{S 2, d s}\right)$ and the primary current of the single-phase transformer $\left(I_{L m, S l}\right)$ are represented. In the BCM operation, the peak value of $I_{L m, S l}$ is reduced because the switching time is shorter than that of the DCM operation. Fig. 20(b) shows the experimental closed waveforms when the mode changes from the DCM operation to the BCM operation. Fig. 20(c) shows experimental closed waveforms when the mode changes from the BCM operation to the DCM operation. When the system enters the BCM operation, the main switch turns on when the main switch-off time ends.

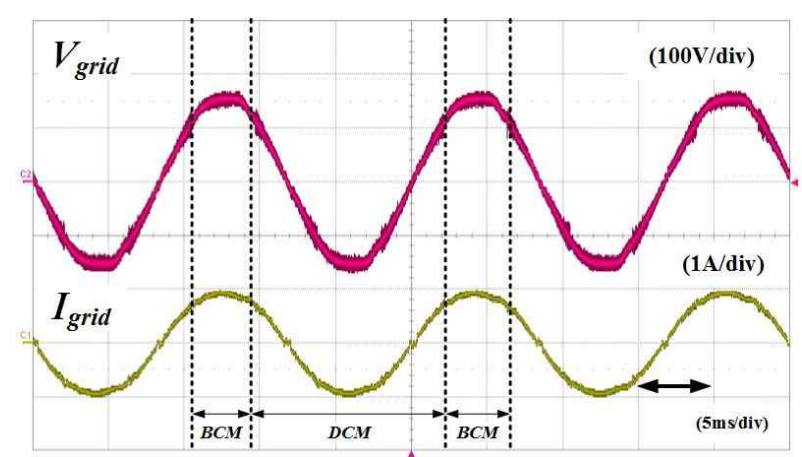

Fig. 21. Grid voltage and grid current waveforms of the dual-mode ILFI.
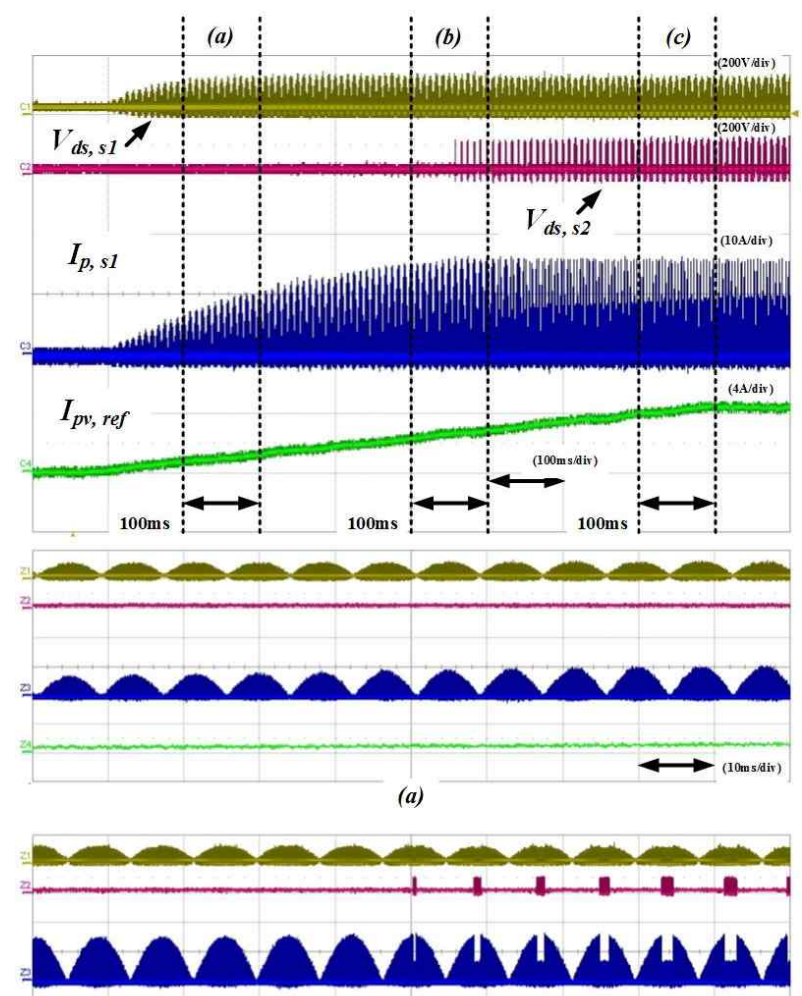

(b)

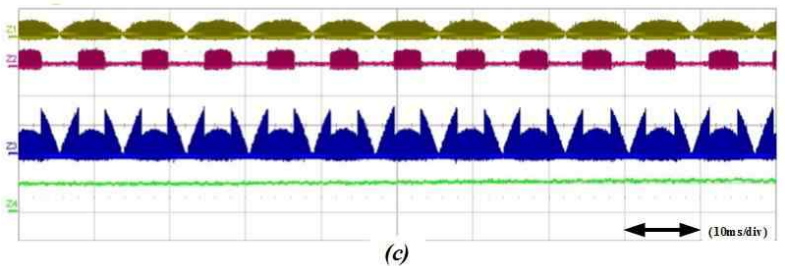

Fig. 22. Experimental waveforms of the proposed current sensorless MPPT control method for the dual-mode ILFI. (a) Operating in the single-phase DCM operation. (b) Entering the dual-mode. (c) Operating in the MPP.

Hence, as shown in Figs. 20(b) and (c), in the interleaved $\mathrm{BCM}$ operation, the switching period is shorter than that of the single-phase DCM operation.

Fig. 21 shows experimental waveforms of the grid voltage and grid current. The output current of the ILFI is a 


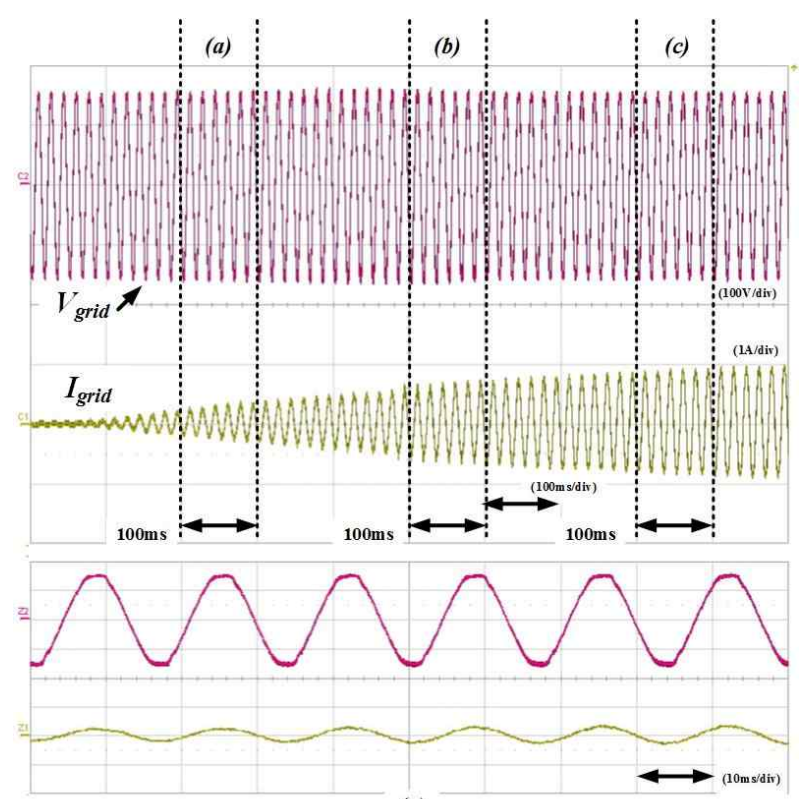

(a)

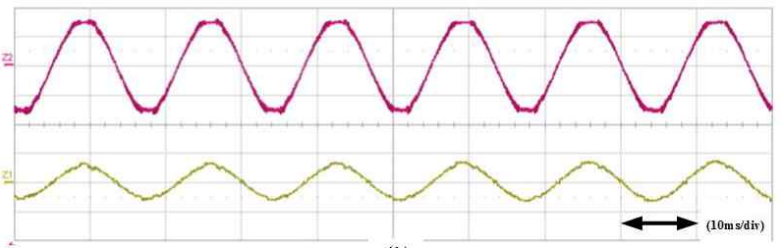

(b)

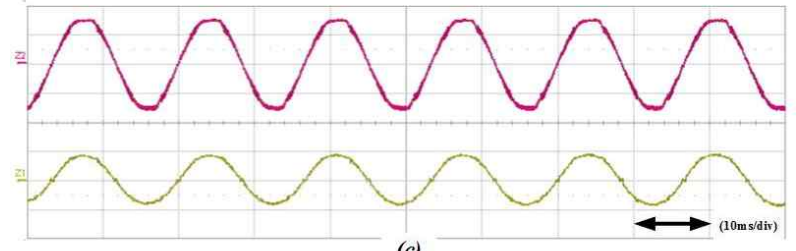

(c)

Fig. 23. Grid waveforms of the proposed MPPT control method for the dual-mode ILFI. (a) Operating in the single-phase DCM operation. (b) Entering the dual-mode. (c) Operating in the MPP.

sinusoidal wave. The phase of the grid voltage is shown to be the same as that of the grid current.

Fig. 22 shows the waveforms of the proposed current sensorless MPPT control method for the ILFI with dual mode. From (12), $I_{p v, a v g}$, which is a DC value, is compared with $I_{p v, r e f}$ for the current control. Therefore, the duty ratio is generated by the current control. Fig. 22(a) shows a closed waveform for the single-phase DCM operation. If the system enters this operation mode, the two-phase flyback inverter does not operate because the system power is less than $P_{\text {ref. }}$ Fig. 22(b) shows a closed waveform when the system power is greater than $P_{r e f}$. If the system enters this operation mode, the dual-mode operation starts. Fig. 20(c) shows a closed waveform when $I_{p v, r e f}$ reaches the MPP.

Fig. 23 shows the grid voltage and grid current waveforms of the proposed current sensorless MPPT control method for the ILFI with dual mode. Since $I_{p v, r e f}$ is increased by the control, the grid current increases. Fig. 23(a) shows a closed

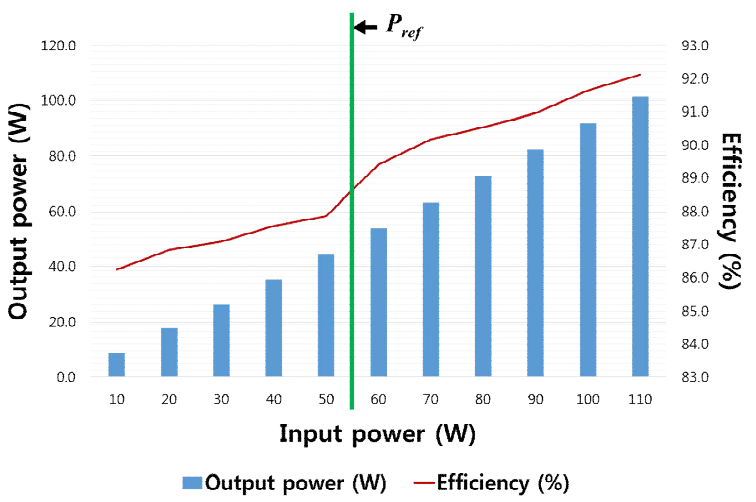

Fig. 24. Efficiency graph of the proposed MPPT control method for the dual-mode ILFI.

waveform for the single-phase DCM operation, and Fig. 23(b) shows a closed waveform when the system power is greater than $P_{r e f}$. Fig. 23(c) shows a closed waveform when $I_{p v, \text { ref }}$ reaches the MPP. As seen in Figs. 22 and 23, the primary current increases by $I_{p v, r e f}$. Therefore, the proposed current sensorless MPPT control method is confirmed with the grid current waveform.

Fig. 24 shows the efficiency of the proposed MPPT control method for dual-mode ILFIs. The efficiency measurement result shows that the maximum efficiency is $92.1 \%$. As shown in Fig. 24, because the conduction loss is decreased by reducing the primary peak current in the interleaved BCM operation, the efficiency rapidly increases in the interleaved $\mathrm{BCM}$ operation.

\section{CONCLUSION}

In the PV-PCS market, many studies on the MIC have been conducted recently because of its benefits such as independent control for reducing the damage caused by solar radiation. Among many the MIC topologies, the dual-mode interleaved flyback topology is the most commonly used topology because of its ease in installation and higher efficiency.

This paper presents a current sensorless MPPT control method for the dual-mode PV module-type ILFI. The conventional MPPT control method for the MIC requires voltage and current sensors. This increases the system cost because of the large size and high price of the sensors. Currently, the price of an interleaved MIC is about $\$ 150$ and an IC type current sensor is about $\$ 8$. The conventional interleaved MIC requires two current sensors for acquiring the current of each phase. In this case, the current sensors account for about $10 \%$ of the total price. When the MIC is used in large PV generation systems, the price of the current sensors cannot be ignored. Therefore, a system has an advantage in price by using the proposed sensorless MPPT control method. Although the proposed control scheme is more complicated, the system size and cost are smaller and cheaper than the conventional method. 
Simulation and experimental results show similar performances and validate the proposed current sensorless MPPT control method for ILFIs.

\section{ACKNOWLEDGMENT}

This work was supported by the 20134030200310 of the Korea Institute of Energy Technology Evaluation and Planning (KETEP) grant funded by the Korea government Ministry of Knowledge Economy.

This work was supported by KETEP (G031462812) which is funded by MKE (Ministry of Knowledge Economy).

\section{REFERENCES}

[1] M. G. Villalva, J. R. Gazoli, and E. R. Filho, "Comprehensive approach to modeling and simulation of photovoltaic arrays," IEEE Trans. Power Electron., Vol. 24, No. 5, pp. 1198-1208 May 2009.

[2] J. S. Lee and K. B. Lee, "Variable DC-link voltage algorithm with a wide range of MPPT for a two-string PV system," Energies, Vol. 6, No. 1, pp. 58-78, Jan. 2013.

[3] H. G. Jeong, G. S. Kim, and K. B. Lee, "Second-order harmonic reduction technique for photovoltaic power conditioning systems using a proportional-resonant controller," Energies, Vol. 6, No. 1, pp. 79-96, Jan. 2013.

[4] J. S. Lee and K. B. Lee, "New modulation techniques for a leakage current reduction and a neutral-point voltage balance in transformerless photovoltaic systems using a three-level inverter," IEEE Trans. Power Electron., Vol. 29, No. 4, pp. 1720-1732, Apr. 2014.

[5] C. Meza, J. J. Negroni, D. Biel, and F. Guinjoan, "Energy-balance modeling and discrete control for single-phase grid-connected PV central inverters," IEEE Trans. Ind. Electron., Vol. 55, No. 7, pp. 2734-2743, Jul. 2008

[6] H. J. Bergveld, D. B"uthker, C. Castello, T. Doorn, A. d. Jong, R. Otten, and K. Waal, " Module-level DC/DC conversion for photovoltaic systems: The delta-conversion concept," IEEE Trans. Power Electron., Vol. 28, No. 4, pp. 2005-2013, Apr. 2013.

[7] S. A. Khajehoddin, A. Bakhshai, and P. Jain, "A novel topology and control strategy for maximum power point trackers and multi-string grid-connected PV inverters," in IEEE Proc. APEC, pp. 173-178, 2008.

[8] A. C. Nanakos, E. C. Tatakis, and Nick P. Papanikolaou, "A weighted-efficiency-oriented design methodology of flyback inverter for AC photovoltaic modules," IEEE Trans. Power Electron., Vol. 27, No. 7, pp. 3221-3233, Jul. 2012.

[9] Z. Liang, R. Guo, J. Li, and A. Q. Huang, "A high-efficiency PV module integrated DC/DC converter for PV energy harvest in FREEDM systems," IEEE Trans. Power Electron., Vol. 26, No. 3, pp. 897-909, Mar. 2011.

[10] A. C. Kyritsis, E. C. Tatakis, and N. P. Papanikolaou, "Optimum design of the current-source flyback inverter for decentralized grid-connected photovoltaic systems," IEEE Trans. Energy Convers., Vol. 23, No. 1, pp. 281-293, Mar. 2007.

[11] Y. H. Ji, D. Y. Jung, J. H. Kim, C. Y. Won, and D. S. Oh, "Dual mode switching strategy of flyback inverter for photovoltaic AC modules," in IEEE Proc. IPEC, pp. 2924-2929, 2010.
[12] Q. Mo, M. Chen, Z. Zhang, Y. Zhang, and Z. Qian, "Digitally controlled active clamp interleaved flyback converters for improving efficiency in photovoltaic grid-connected micro-inverter," in IEEE Proc. APEC, pp. 555-562, 2012

[13] T. Esram and P. L. Chapman, "Comparison of photovoltaic array maximum power point tracking techniques," IEEE Trans. Energy Convers., Vol. 22, No. 2, pp. 439-449, Jun. 2007.

[14] Y. C. Chang, C. L. Kuo, K. H. Sun, and T. C. Li, "Development and operational control of two-string maximum power point trackers in DC distribution systems," IEEE Trans. Power Electron., Vol. 28, No. 4, pp. 1852-1861, Apr. 2013.

[15] G. C. Hsieh, H.-I Hsieh, C. Y Tsai, C. H. Wang, "Photovoltaic power increment aided incremental conductance MPPT with two-phased tracking," IEEE Trans. Power Electron., Vol. 28, No. 6, pp. 2895-2910, Jun. 2013.

[16] Q. Mei, M. Shan, L. Liu, and J. M. Guerrero, "A novel improved variable step-size incremental-resistance MPPT method for PV systems," IEEE Trans. Ind. Electron., Vol. 58, No. 6, pp. 2427-2434, Jun. 2011

[17] F. I. Simjee and P. H. Chou, "Efficient charging of supercapacitors for extended lifetime of wireless sensor nodes," IEEE Trans. Power Electron., Vol. 23, No. 3, pp. 1526-1536, May 2008.

[18] I. Laird and D. D. C. Lu, "High step-up DC/DC topology and MPPT algorithm for use with a thermoelectric generator," IEEE Trans. Power Electron., Vol. 28, No. 7, pp. 3147-3157, Jul. 2013.

[19] S. B. Kjaer, "Evaluation of the 'hill climbing' and the 'incremental conductance' maximum power point trackers for photovoltaic power systems," IEEE Trans. Energy Convers., Vol. 27, No. 4, pp. 922-929, Dec. 2012.

[20] W. M. Lin, C. M. Hong, and C. H. Chen, "Neural-network-based MPPT control of a stand-alone hybrid power generation system," IEEE Trans. Power Electron., Vol. 26, No. 12, pp. 3571-3581, Dec. 2011.

[21] T.-F. Wu, C.-H. Chang, and Y.-H. Chen, "A fuzzy-logic-controlled single-stage converter for PV-powered lighting system applications," IEEE Trans. Ind. Electron., Vol. 47, No. 2, pp. 287-296, Apr. 2000.

[22] B. Yang, W. Li, Y. Zhao, and X. He, "Design and analysis of a grid-connected photovoltaic power system," IEEE Trans. Power Electron., Vol. 25, No. 4, pp. 992-1000, Apr. 2010.

[23] N. Kasa, T. Iida, and L. Chen, "Flyback inverter controlled by sensorless current MPPT for photovoltaic power system," IEEE Trans. Ind. Electron., Vol. 52, No. 4, pp. 1145-1152, Aug. 2005.

[24] T. Esram and P. L. Chapman, "Comparison of photovoltaic array maximum power point tracking techniques," IEEE Trans. Energy Convers., Vol. 22, No. 2, pp. 439-449, Jun. 2007.

[25] Y. Zhang, X. F. He, Z. Zhang, and Y. F. Liu "A hybrid control method for photovoltaic grid-connected interleaved flyback micro-inverter to achieve high efficiency in wide load range," in IEEE Proc. APEC, pp. 751-756, 2013

[26] Z. Zhang, X. F. He, and Y. F. Liu "An optimal control method for photovoltaic grid-tied-interleaved flyback microinverters to achieve high efficiency in wide load range," IEEE Trans. Power Electron., Vol. 28, No. 11, pp. 5074-5087, Nov. 2013. 


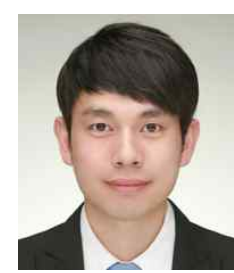

June-Hee Lee received his B.S. degree in Electronic Engineering from Ajou University, Suwon, Korea, in 2013. He is presently working toward his M.S. degree in Electronic Engineering at Ajou University. His current research interests include power conversion and grid-connected systems.

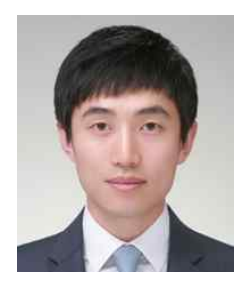

June-Seok Lee received his B.S. and M.S. degrees in Electronic Engineering from Ajou University, Suwon, Korea, in 2011 and 2013, respectively. He is presently working toward his Ph.D. degree at Ajou University. His current research interests include grid-connected systems, multilevel inverters and reliability.

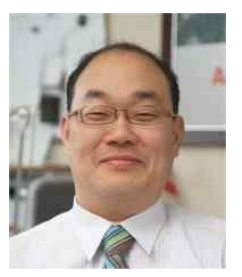

Kyo-Beum Lee received his B.S. and M.S. degrees in Electrical and Electronic Engineering from Ajou University, Suwon, Korea, in 1997 and 1999, respectively. He received his $\mathrm{Ph} . \mathrm{D}$. degree in Electrical Engineering from Korea University, Seoul, Korea, in 2003. From 2003 to 2006, he was with the Institute of Energy Technology, Aalborg University, Aalborg, Denmark. From 2006 to 2007, he was with the Division of Electronics and Information Engineering, Chonbuk National University, Jeonju, Korea. In 2007 he joined the Department of Electrical and Computer Engineering, Ajou University. He is an Associated Editor of the IEEE Transactions on Power Electronics and the Journal of Power Electronics. His current research interests include electric machine drives and renewable power generation. 